\title{
EDIÇÕES BILÍNGUE (PORTUGUÊS/FRANCÊS) E UNILÍNGUE (FRANCÊS) D'O ALIENISTA DE MACHADO DE ASSIS: DOMESTICAÇÃO, ESTRANGEIRIZAÇÃO E MODALIDADES LINGUÍSTICAS EM DUAS TRADUÇÕES DE MESMA AUTORIA
}

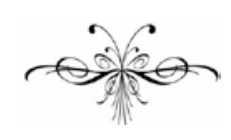

\author{
JosÉ RoBERTO ANDRADE FÉRES
}

Resumo: Este artigo analisa duas traduções d'O Alienista, de Machado de Assis, para a língua francesa, ambas feitas pela mesma tradutora, Maryvonne Lapouge-Pettorelli, uma delas publicada em uma edição bilíngue (português/francês) e a outra em uma edição unilíngue (francês). O objetivo é investigar, a partir dos termos de Lawrence Venuti, se uma delas seria mais estrangeirizadora ou domesticadora que a outra, sobretudo por se conjeturar que uma edição bilíngue geralmente apresente estratégias que pendem para a estrangeirização, já que o seu consumidor tende a ter um maior interesse pela língua e pela cultura estrangeira que o consumidor de uma edição unilíngue. Para tal estudo, faz-se um breve exame dos elementos paratextuais das edições em questão e, lançando-se mão da teoria semântica de Bernard Pottier sobre a modalização, analisam-se as modalidades linguísticas (que são, segundo Maria Helena de Araújo Carreira, as marcas materiais da subjetividade do enunciador) apresentadas no texto original em comparação com aquelas que figuram nas duas traduções, buscando-se dali depreender o grau de subjetividade da própria tradutora em cada uma das edições. Recorre-se a tal teoria pelo fato

\begin{abstract}
This paper analyzes two translations of $O$ Alienista (by Machado de Assis) into French, both made by the same translator, Maryvonne LapougePettorelli, one published in a bilingual edition (Portuguese/French) and the other in a monolingual edition (French). The aim is to investigate, through the terms of Lawrence Venuti, if one of them would be more foreignizing or domesticating than the other, especially from the conjecture that a bilingual edition presents strategies that usually lean to foreignization, as its consumer tends to have a greater interest in the foreign language and culture than the consumer of a monolingual edition. For this study, a brief examination of the paratextual elements of the editions is made and, based on Bernard Pottier's semantic theory about modalization, the linguistic modalities (which are, according to Maria Helena de Araújo Carreira, the material marks of the enunciator's subjectivity) presented in the original text and compared with those contained in the two translations are analyzed, in the attempt to infer from it the degree of subjectivity of the translator itself in each edition. What justifies the use of this theory is the fact that, unlike the foreignizing translators, the domesticating ones take greater freedom
\end{abstract}


de que, ao contrário do tradutor estrangeirizador, o domesticador toma uma maior liberdade para adaptar o original à sua própria língua e cultura, para se distanciar da subjetividade do autor e, por conseguinte, deixar marcas de sua própria subjetividade na tradução.

Palavras-chave: Alienista; tradução; estrangeirização; domesticação; modalização. to adapt the original text to their own language and culture, to distance themselves from the author's subjectivity and therefore leave the marks of their own subjectivity in the translation.

\begin{abstract}
Keywords: Alienista; translation; foreignization; domestication;
\end{abstract}

$\mathrm{E}$ m “Tradução e ilusão”, Paulo Henriques Britto (2012, p. 21) nos recorda que os termos domesticação e estrangeirização, em relação à atividade tradutória, apesar de recentemente criados pelo teórico norte-americano Lawrence Venuti, advêm de "duas concepções de tradução [que] foram distinguidas há duzentos anos pelo pensador alemão Friedrich Schleiermacher”. Tais concepções são assim explicadas por Britto (2012, p. 21):

A tradução domesticadora visa facilitar o trabalho do leitor, modificando tudo aquilo que lhe poderia causar estranheza, aproximando o texto do universo linguístico e cultural que já lhe é familiar. A estratégia estrangeirizadora faz o contrário: ela mantém muitas das características originais do texto referências nada óbvias para o leitor da tradução, recursos estilísticos desconhecidos na cultura-alvo, até mesmo alguns elementos do idioma-fonte - com o intuito de aproximar o leitor do universo linguístico e cultural da obra original.

Relembrando e reformulando agora, por nossa vez, as palavras do próprio Venuti (1995), a tradução domesticadora pretende oferecer uma leitura corrente, fluida, sem entraves, durante a qual não se tropece em particularidades da cultura estrangeira que possam incomodar o leitor da tradução. Já a estrangeirizadora propõe o oposto, trazer à tona as diferenças entre as culturas, dar ao leitor da tradução o gosto do estranhamento e, por conseguinte, da descoberta daquilo que não lhe é familiar, mesmo que seja a custo de pausas para questionamento, demandando uma leitura mais atenta e minuciosa. E é assim, sob a luz de tais concepções, que tencionamos investigar nossos objetos de estudo, duas traduções francesas d'O Alienista de Machado de Assis, porém, por incrível que pareça, saídas da pena de uma mesma tradutora, Maryvonne Lapouge-Pettorelli. Perguntamo-nos aqui se uma delas poderia ser mais domesticadora ou estrangeirizadora que a outra.

Tal pergunta sobre L'Aliéniste nos foi inspirada pelo fato de se apresentar, uma das traduções, em uma edição bilíngue (português/francês) (1992) ${ }^{1}$ e, a outra,

\footnotetext{
${ }^{1}$ As citações do texto em português (de Machado de Assis) serão seguidas pela data e pelo número de página - entre parênteses - referente a esta edição bilíngue; as citações da tradução da última serão seguidas pela data e pelo
} 
unilíngue (somente em francês) (2005) ${ }^{2}$. No momento em que lemos os respectivos títulos do primeiro capítulo - "Où il est raconté comment Itaguaí se dota d'un asile d'aliénés” (1992, p.17) e “Où il est raconté comment Itaguaï s'enrichit d'une maison des fous” (2005, p. 25) -, logo conjeturamos que a edição bilíngue (de 2005) seja mais domesticadora que a unilíngue (de 1992), por uma razão muito simples: quando "Itaguaí” (1992), com o acento agudo da língua de origem (estranho à língua francesa no caso de um î), transforma-se em "Itaguaï” (2005), com um trema (ï, familiar para o francês), impossível não supor que haja uma preocupação em domesticar o texto da edição unilíngue, em, digamos, afrancesá-lo, adaptá-lo à cultura que vai recebê-lo, facilitar, neste caso específico, a pronúncia da palavra, sem que o leitor da tradução tenha que se questionar sobre o assunto, poupando-o - ou privando-o - da novidade que lhe representaria esse í do português.

Claro que, em geral, é de se esperar que o consumidor de uma edição bilíngue esteja buscando justamente se estrangeirizar, poder ler tanto o original quanto a tradução e, dessa maneira, embrenhar-se nas profundezas da língua e da cultura estrangeiras. Por outro lado, não nos parece tão óbvio que uma edição unilíngue tenha de ser necessariamente domesticadora, motivo pelo qual resolvemos redigir este artigo.

Para a análise comparativa dos aspectos estrangeirizadores e domesticadores dessas traduções, além de, no fim destas páginas, examinarmos brevemente os elementos paratextuais das duas edições (notas de rodapé, prefácio e outros), faremos um estudo mais detalhado de um trecho d'O Alienista em concomitância com as duas traduções mencionadas, trecho que nos parece bastante exemplar de todo o corpus e suficientemente esclarecedor para a questão a que nos propomos responder. Para a investigação de tal excerto, tomaremos como base a teoria semântica de Bernard Pottier (1992) sobre a modalização.

A fim de melhor nos explicarmos, dado que as estratégias domesticadoras consistem em transformar o estrangeiro em algo familiar para o leitor da tradução, elas deverão deixar transparecer no texto traduzido algo que não vem do autor, não vem do original, e sim do próprio tradutor, marcas de sua própria subjetividade. E como reconhecer tais marcas? Segundo Maria Helena de Araújo Carreira (2001, p. 192), estudiosa do teórico citado no parágrafo anterior,

as modalidades linguísticas - que através de uma grande variedade de meios linguísticos exprimem a posição do enunciador relativamente àquilo que enuncia [...] - constituem o objeto de estudo por excelência para a abordagem da expressão linguística da subjetividade.

Compartilhando de sua opinião, é também a partir das categorias levantadas e analisadas no estudo de sua autoria supracitado que estruturaremos o nosso.

As modalidades linguísticas são a marca material da subjetividade do enunciador no enunciado, é aquilo que ele imprime de si no texto - na escolha das palavras, da estrutura gramatical etc. -, seus julgamentos de valor, suas certezas e incertezas, sua tomada de posição em relação ao mundo referencial. Nas palavras de Carreira (1997, p. 236), "la Modalisation est une classe liée aux opérations énonciatives [...] aux 'manipulations' des éléments structurés de base, compte tenu de

\footnotetext{
${ }^{2}$ As citações da tradução contidas nesta edição unilíngue serão seguidas pela data e pelo número de página - entre parênteses.
} 
ce que le JE valorise, selon ses visées comunicatives”3. E, ainda referindo-nos à mesma teórica, eis um resumo das modalidades de Pottier que utilizaremos aqui e as zonas que elas englobam:

1. modalidade alética: domínio da existência, sem referência ao julgamento da enunciação (cf. impossível/possível e suas gradações). Em geral a modalidade alética combina-se com a epistêmica;

2. modalidade epistêmica: domínio do cognitivo (cf. certo/incerto e suas gradações);

3. modalidade deôntica: domínio do dever (cf. obrigatório/proibido e suas gradações);

4. modalidade axiológica: domínio do julgamento, da apreciação (cf. valorização/desvalorização e suas gradações) (CARREIRA, 2001, p. 193).

Dada a pista indicada pela exposição da primeira das modalidades, é necessário ressaltar que não é unicamente ela que pode combinar-se com uma outra ou com outras modalidades. Logo de partida, evidencia-se que o julgamento, a apreciação (axiológica) pode atuar, conforme diz Pottier (1992, p. 206), "sur tout ce qui est formulé" ${ }^{4}$, sobre qualquer enunciado, seja qual for a modalidade ali presente. De onde chega-se à conclusão de que existem modalidades complexas, em que várias delas se combinam, por exemplo, em uma mesma lexia. Seguindo com Carreira (2001, p. 159) e sua constatação de que "a combinatória modal é uma realidade discursiva” e "o estudo de modalidades simples terá de se prolongar no das modalidades complexas”, buscaremos investigar também essas no nosso corpus.

Outro ponto da teoria a ser sublinhado é o de que as modalidades podem "se couler dans toutes sortes de moules syntaxiques” (POTTIER, 1992, p. 206) ; ou seja, os meios linguísticos para se expressar a subjetividade, uma modalidade, são inumeráveis, até mesmo, no caso da escrita, uma "typographie phatique" (POTTIER, 1992, p. 218) ${ }^{6}$ pode ser um indício - e é bem o que veremos em um dos dados analisados mais à frente, onde uma vírgula - não-obrigatória - chama a atenção do leitor, sugerindo uma motivação semântica do autor, passível, porém, de diferentes interpretações, justamente por não ser explicitada.

Quanto às diferentes interpretações, elas nos levam a uma última nota sobre a teoria de Pottier, agora sobre a tradução em si. Segundo ele, o tradutor passa primeiro pelo percurso do leitor - percurso semasiológico, de compreensão no nível da conceitualização - e, só depois, pelo percurso do escritor - percurso onomasiológico, de semiotização, do nível conceitual ao texto propriamente dito -; o tradutor é no princípio interpretante e em seguida enunciador (POTTIER, 2001, p. 44-45). Portanto, o resultado final, o texto traduzido, apresentará necessariamente traços da subjetividade do tradutor, de sua interpretação individual, por maior que seja o seu

\footnotetext{
3 Nossa tradução: “a Modalização é uma categoria ligada às operações enunciativas [...] às 'manipulações' dos elementos estruturais de base, levando-se em conta o que o EU valoriza, segundo seus objetivos comunicativos".

${ }^{4}$ Nossa tradução: "sobre tudo o que se formula”.

${ }^{5}$ Nossa tradução: “se despejar em todo tipo de fôrmas sintáticas”.

${ }^{6}$ Nossa tradução: “tipografia fática”.
} 
conhecimento sobre a obra a ser traduzida e/ou seu desejo de não deixar transparecer a sua própria subjetividade.

Assim, conscientes de que outros apontamentos teóricos poderão ser feitos mais abaixo, passemos à análise do trecho selecionado n'O Alienista e nas duas traduções aqui estudadas.

O episódio que escolhemos analisar - parte que nos parece refletir bastante o todo - é aquele em que se relata o encontro do doutor Simão Bacamarte, o alienista, com o boticário, o senhor Soares, encontro que se dá na Casa Verde, o asilo de loucos de Itaguaí. Em resumo, o boticário, tendo sido chamado pelo doutor, vem vê-lo às pressas, pois pensava tratar-se de algum problema que poderia ter ocorrido com a sua própria esposa; mas o que Simão ansiava por lhe contar era a sua descoberta de que os loucos são muito mais numerosos do que imaginava. Quanto à preocupação de Soares em relação à sua esposa, explica-se pelo fato de ela estar de viagem naquele momento, no Rio de Janeiro, acompanhando a "consorte"7 de Simão.

Ao longo de nossa análise, evidenciando e esclarecendo a modalização nas escolhas da tradutora para suas duas versões francesas, comparando-as umas com as outras e com as modalidades encontradas no texto de Machado de Assis, tentaremos acomodar os resultados nas seguintes categorias: (I) eliminação, (II) acréscimo ou (III) alteração do tipo de modalidade; (IV) alteração do grau da modalidade, por sua (IVa) atenuação ou por seu (IVb) reforço; (V) alteração da incidência da modalidade; (VI) profundas reformulações sintagmáticas (VIa) sem alteração da modalidade e (VIb) com alteração da modalidade ${ }^{8}$. O número de referência das categorias aparecerá entre parênteses, como na última frase, em cada um dos exames.

Abaixo, portanto, o excerto que será examinado, marcado por letras que correspondem a nosso passo seguinte, àquilo que será objeto da análise propriamente dita. Demos preferência a essa estrutura - e não à subdivisão seguindo as categorias enumeradas no parágrafo anterior - porque, da mesma forma que as modalidades podem ser complexas, combinarem-se entre si, existem casos que podemos considerar, por exemplo, tanto como uma (I) eliminação quanto como uma (III) alteração do tipo de modalidade, dependendo dos sentidos que se atribuem ao que está implícito no texto. Daí a importância de se relembrar que, como linguistas, somos também “intérpretes dessas mensagens" (JAKOBSON, 2010, p. 66), o que se complica ainda mais neste trabalho: somos, ao mesmo tempo, interpretantes (segundo o termo de Pottier) do texto de Machado de Assis - do qual a tradutora também foi uma interpretante -; interpretantes do texto - de 1992 - de um interpretanteenunciador - a tradutora, que foi também interpretante do original antes de se tornar enunciador em sua tradução -; e, finalmente, somos interpretantes do texto - de 2005 - de um reinterpretante-reenunciador - a retradutora, que foi interpretante também da

\footnotetext{
${ }^{7}$ Esta palavra já nos serve de exemplo prévio da análise: nos momentos em que o narrador se focaliza em dona Evarista, porém falando de Simão, emprega-se para este a lexia “marido” (por exemplo, 1992, p. 26), que é traduzida nas duas edições por “époux” (1992, p. 27; 2005, p. 29); no caso contrário, em que se fala dela focando-se em Simão, Evarista é sua “consorte” (1992, p.18), o que é traduzido por “épouse” (1992, p. 19; 2005, p. 26). "Épouse” é, no entanto, uma palavra não-modalizada, o feminino de “époux”, não contém o implícito ponto de vista de Simão sobre a sua companheira: muito mais interessado na ciência que no amor, a mulher é para ele uma simples "consorte”, parasinônimo do termo legal "cônjuge", e substantivo de dois gêneros - como se não lhe interessasse o sexo de sua esposa, como se Evarista fosse semelhante a um homem, a um sócio... Ambas as traduções eliminam assim a modalidade axiológica de apreciação negativa contida em "consorte”.

8 Categorias inspiradas naquelas propostas nos estudos de Carreira supracitados.
} 
sua primeira tradução antes de se tornar enunciador em sua retradução. Com tantas complicações, decidimos dispor o original e as traduções lado a lado, a fim de facilitar a comparação dos textos.

\begin{tabular}{|c|c|c|}
\hline $\begin{array}{c}\text { Machado de Assis (1992, } \\
\text { p. 56) }\end{array}$ & $\begin{array}{l}\text { Lapouge-Pettorelli } \\
\text { (1992, p. 57) }\end{array}$ & $\begin{array}{l}\text { Lapouge-Pettorelli } \\
(2005, \text { pp. 40-41) }\end{array}$ \\
\hline 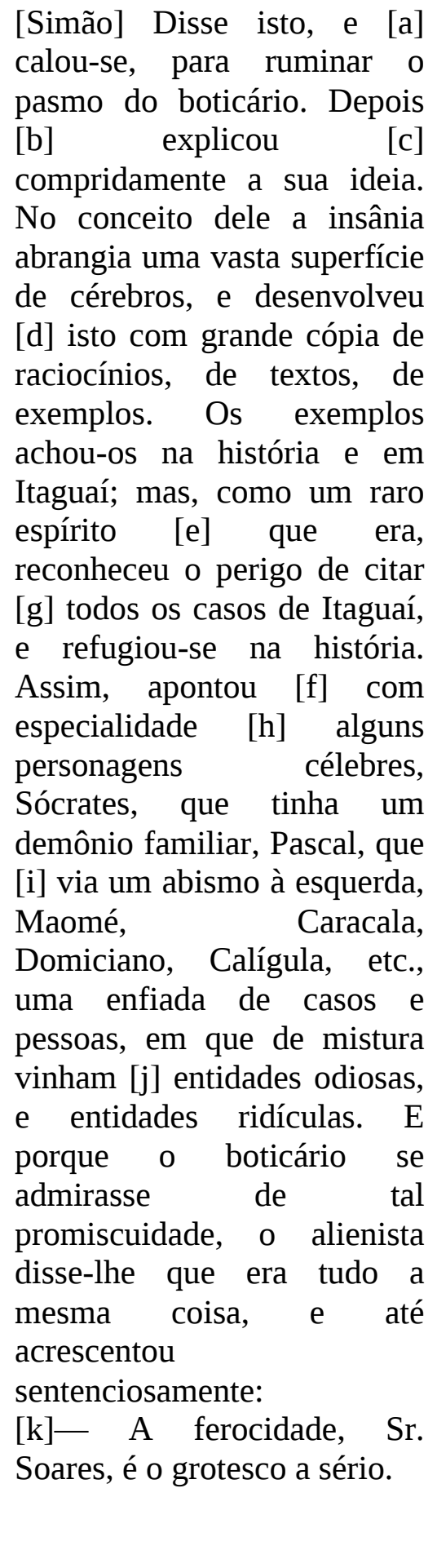 & $\begin{array}{l}\text { Ceci dit, il se tut pour } \\
\text { savourer la stupéfaction } \\
\text { de l'apothicaire. Puis il } \\
\text { développa longuement } \\
\text { son propos. La } \\
\text { démence, à son avis, } \\
\text { embrassait un vaste } \\
\text { territoire de cerveaux } \\
\text { humains, présomption } \\
\text { qu'il étaya à grand } \\
\text { renfort d'arguments, de } \\
\text { textes, d'exemples. Les } \\
\text { exemples, il les trouva } \\
\text { dans l'histoire et dans } \\
\text { Itaguaï, mais, en homme } \\
\text { d'un esprit rare comme } \\
\text { il était, il saisit le danger } \\
\text { de citer tous les cas } \\
\text { d'Itaguaï, et il se rabattit } \\
\text { sur l'histoire. Il désigna } \\
\text { ainsi quelques } \\
\text { personnages célèbres: } \\
\text { Socrate, qui avait un } \\
\text { démon familier, Pascal, } \\
\text { qui imaginait voir un } \\
\text { abîme sur sa gauche, } \\
\text { Mahomet, Caracalla, } \\
\text { Domitien, Caligula, etc., } \\
\text { une kyrielle de cas et de } \\
\text { personnes, chez lesquels } \\
\text { venaient se mélanger } \\
\text { des entités odieuses et } \\
\text { des entités ridicules. Et } \\
\text { comme l'apothicaire } \\
\text { s'étonnait d'une telle } \\
\text { promiscuité, l'aliéniste } \\
\text { lui répondit que c'était } \\
\text { tout cela du pareil au } \\
\text { même, et il alla jusqu'à } \\
\text { ajouter d'un air entendu: }\end{array}$ & $\begin{array}{l}\text { Sur quoi il marqua un } \\
\text { silence pour savourer la } \\
\text { stupéfaction de } \\
\text { l'apothicaire. Puis il } \\
\text { entreprit de développer } \\
\text { son propos de façon } \\
\text { détaillée. La démence, à } \\
\text { son avis, concernait une } \\
\text { très large sphère de } \\
\text { l'humanité, présomption } \\
\text { qu'il étaya à grand renfort } \\
\text { d'arguments, de textes, } \\
\text { d'exemples. Fournis ceux- } \\
\text { ci par l'histoire et par } \\
\text { Itaguaï; mais, en homme } \\
\text { d'un rare esprit, il saisît } \\
\text { [sic] le danger de faire } \\
\text { état de la moisson de cas } \\
\text { glanés dans le pays } \\
\text { même. Il se rabattit sur } \\
\text { l'histoire, faisant servir à } \\
\text { sa démonstration nombre } \\
\text { de personnages célèbres, } \\
\text { tels Socrate, qui avait un } \\
\text { démon familier, Pascal, } \\
\text { lequel imaginait avoir } \\
\text { [sic] un abîme sur sa } \\
\text { gauche, Mahomet, } \\
\text { Caracalla, Domitien, } \\
\text { Caligula et d'autres } \\
\text { encore, toute une série de } \\
\text { cas et de personnes } \\
\text { présentant, mêlés à leur } \\
\text { indubitable génie, des } \\
\text { traits souvent odieux, et } \\
\text { parfois ridicules. Et } \\
\text { comme l'apothicaire } \\
\text { s'étonnait de pareille } \\
\text { promiscuité, l'aliéniste lui } \\
\text { dit que tout cela était du }\end{array}$ \\
\hline
\end{tabular}




\begin{tabular}{|l|lr|l|l|}
\hline - La férocité, monsieur & pareil au même, jusqu'à \\
Soares, & c'est & le & conclure d'un air entendu: \\
grotesque & doublé & de & - Sont féroces, monsieur \\
sérieux. & & $\begin{array}{l}\text { Soares, les grotesques qui } \\
\text { se prennent au sérieux. }\end{array}$
\end{tabular} \mid

[a] Logo no princípio, pode-se perceber que a tradutora, conquanto mantenha o valor de "calou-se" na primeira versão ("se tut"), enfatiza o silêncio na segunda ("marqua un silence"), reforça a sua importância, o seu valor, que sequer estava presente no neutro "calou-se”. Assim, temos em 2005 um (II) acréscimo de uma modalidade axiológica que não figurava nem no original nem na tradução de 1992.

[b] "Explicou”, visto que é um verbo que pressupõe um conhecimento a ser compartilhado, é modalizado epistemicamente. Isso é mantido na primeira versão por "développa” (desenvolveu); porém, na segunda, com "entreprit de développer" (tentou/começou a desenvolver), estamos face a três modificações em razão do "entreprit de" (tentou/começou a): (II) um acréscimo de um querer que tende a um dever, de uma modalidade deôntica; (II) um acréscimo também de uma axiologia de desvalorização do conhecimento do doutor, pois “entreprit de” é igualmente tentar, mas não necessariamente conseguir; e, por conseguinte, (IVa) uma atenuação no grau da modalidade epistêmica, dado que passamos de uma certeza, de um conhecimento adquirido a se compartilhar, a um saber mais incerto, mais discutível quanto à sua pertinência.

[c] Quando se explica “compridamente” uma coisa, ou quem explica é muito maçante, entediante, ou quem escuta é, supostamente, muito ignorante, precisa de uma explicitação e uma repetição intermináveis para entender o que está sendo explicado. Essa apreciação negativa encontra seu par na modalidade axiológica intrínseca a "longuement” (longamente, 1992). Entretanto, o “de façon détaillée” (de maneira detalhada, 2005), ou (I) elimina a modalidade, pois pode ser entendido como neutro, sem julgamento de valor algum, ou (III) altera o seu tipo: apesar de continuar sendo uma modalidade axiológica, ela se inverte, já que “de façon détaillée” (de maneira detalhada) não tem uma conotação negativa, embora positiva possa ter, significando uma preocupação com a clareza da exposição verbal feita pelo doutor Bacamarte.

[d] Vê-se, através de "desenvolveu isto" (o seu conceito de que "a insânia...”), mais um caso de um duplo (II) acréscimo de modalidade: tendo sido “isto” traduzido por "présomption” (presunção), nas duas edições, revela-se uma apreciação (axiológica) negativa concernente àquele conceito de insânia de Simão, muito presunçoso, além de impor uma desconfiança quanto à certeza de seu saber (epistêmica).

[e] Por um lado, doutor Bacamarte, “como um raro espírito”, modalizado axiologicamente pelo adjetivo de apreciação positiva "raro", raridade ainda reforçada por "que era”, continua o sendo (“comme il était") em 1992, mas não é senão um "homme d'un rare esprit" em 2005: (IVa) atenuou-se ali o grau da modalidade presente no original. Por outro lado, podemos interpretar esse "que era" como uma ironia, ou seja, como se ele não fosse "um raro espírito" coisíssima nenhuma, de forma que teríamos partido de uma depreciação de "raro espírito" rumo à sua valorização em 2005, por causa da perda dessa marca irônica que seria "que era”: tratar-se-ia de uma (III) alteração do tipo de modalidade, bem semelhante à segunda opção sugerida para a análise de [c]. 
[f] A ênfase promovida por "com especialidade” ao verbo “apontou” comporta, a nosso ver, duas modalidades combinadas (epistêmica e axiológica): a especialidade pode referir-se ao domínio de um conhecimento por parte do doutor (modalidade epistêmica) e ao caráter especial, único, incomparável (axiológica positiva) tanto desse conhecimento quanto das celebridades que ele apontou. Entretanto, se temos em uma mão a primeira tradução, onde essas modalidades se perderam, foram (I) eliminadas por completo do texto, temos na outra mão a segunda tradução, que demanda de nós uma atenção redobrada.

Se procurarmos bem, algumas linhas depois, encontramos algo que parece ter vindo da imaginação da tradutora, pois é difícil localizar o seu correspondente no texto de Machado. Mas imaginação e criatividade parecem-nos duas coisas distintas quando se trata de tradução. Acreditamos que "mêlés à leur indubitable génie" (misturados à sua indubitável genialidade) desloca para o fim da frase de 2005 aquele "com especialidade" que se encontrava no início da de Machado de Assis, e que havia se perdido em 1992: isso é criatividade, e não imaginação, devaneio, coisa de lunático; e esse é o tipo de criatividade que, geralmente, só se permite uma tradução domesticadora. Dessa maneira, o que aqui ocorre é, em concomitância, uma (VIa) profunda reformulação sintagmática sem alteração da modalidade; uma (V) alteração da incidência da modalidade - pois, se esse caráter especial podia, antes, incidir sobre Simão e sobre aquelas primeiras celebridades citadas, agora toma por alvo "toute une série de cas et de personnes” (toda uma série de casos e de pessoas) -; e, para encerrar este caso, um (IVb) reforço no grau de positividade da modalidade axiológica evidente em "especialidade”, substantivo que é indubitavelmente mais brando que um “indubitable génie” (indubitável genialidade).

[g] (Parecerá estranho ao leitor que tiver percebido, na ordem das letras dispostas no quadro acima, um [g] precedendo um [f]: é que precisávamos desse último parágrafo para iniciar este.) Como foi dito, imaginação e criatividade não são, no nosso entender, a mesma coisa: com a leitura de "todos os casos de Itaguaí" seguida por "tous les cas d'Itaguaï" (1992), nada fora do normal, nem criativo nem imaginativo; mas "la moisson de cas glanés dans le pays même” (2005) é, para nós, só imaginário, é, aliás, imaginação demais, é criativo demais, mas criativo a partir de uma imaginação que é própria à tradutora, que não encontra sua fundamentação em nada que esteja no texto original: não se toma ali uma matéria-prima presente no original e se a transforma na tradução, mas cria-se uma nova matéria, inexistente no original, advinda somente da imaginação da própria tradutora.

De volta à análise, “todos os casos” apresenta uma modalidade axiológica de valorização positiva (100 \% dos casos) que é retomada literalmente por “tous les cas” (1992), mas que sofre uma (III) alteração de tipo em 2005, tornando-se negativa: traduziríamos "la moisson de cas glanés dans le pays même" como, aproximadamente - e exagerando, da mesma maneira, nas modalidades -, casos que foram catados nos restos da colheita dessa terrinha mesmo, cujos frutos são esses caipiras de última categoria...

[h] Algo bem simples: em 2005, "nombre de personnages” (numerosos personagens) (IVb) reforça o grau de valorização da modalidade axiológica reconhecível em “alguns” e “quelques” (1992), que significam poucos, em pequeno número.

[i] Sabemos muito bem que um lunático (na concepção de "louco" do termo) vive realmente na lua; ele está aqui, na nossa frente, na terra, e não está ao mesmo tempo; está na lua, na sua lua, que, por mais virtual que ela nos pereça ser, é, para ele, 
tão real (e atual) quanto a nossa terra, sendo esta virtual para ele. E o narrador d'O Alienista não duvida disso de forma alguma ao comentar sobre "Pascal, que via um abismo à esquerda": Pascal via-o realmente, o abismo estava lá, existia, nesse enunciado exemplar da modalidade alética combinada com a epistêmica: o abismo existe (alética) e Pascal tem certeza disso (epistêmica), pois o vê.

Refletindo sobre a diferença entre os conceitos de "vrai universel" e "vrai épistémique” (verdadeiro universal e verdadeiro epistêmico) para Pottier (1992, p. 209-211), é como se, para Pascal, o "abismo à esquerda” fosse um "vrai universel”, desprovido de qualquer julgamento, pois ele não coloca em questão sua existência, enquanto que nós, sãos de mente, nos questionamos: será que Pascal não sabe que esse abismo à esquerda não existe?... E é exatamente isso que a tradutora, tão sã de mente quanto nós, faz nas duas edições, ela insere a dúvida, a incerteza, por meio do verbo imaginar, transformando o "vrai universel" do enunciado original em um "vrai epistémique" ("Pascal, qui imaginait voir un abîme" [1992]; "Pascal, lequel imaginait avoir [sic] un abîme”[2005]), o que implica uma (I) eliminação da modalidade alética e uma (IVa) atenuação da certeza contida na modalidade epistêmica do original.

[j] Parecem apresentar-se no mesmo nível, no texto de Machado de Assis, "entidades odiosas, e entidades ridículas", da mesma forma - palavra por palavra que em "des entités odieuses et des entités ridicules" (1992). Mas é preciso lembrar Pottier (1992, p. 220) e seu comentário de que "la hiérarchie que l'énonciateur impose aux différentes composantes de son discours"9 tem a ver com a modalidade axiológica, com a importância que o enunciador dá a um ou outro componente de seu discurso: daí nos perguntarmos o porquê das "odiosas" entidades virem antes das "ridículas".

Embora não consigamos notar claramente essa modalidade no texto original, - lembrando-se também da "typographie phatique” (tipografia fática) citada mais acima - é possível interpretar que a vírgula entre "entidades odiosas, e entidades ridículas” representa, implicitamente, e reforça uma marca de hierarquização de tais entidades, de julgamento de valor, pois nenhuma norma da língua portuguesa obriga que a vírgula venha antes do "e"; e é assim que a deve ter compreendido a tradutora em 2005, escrevendo "souvent odieux, et parfois ridicules" (frequentemente odiosas, e por vezes ridículas). Desta feita, temos duas opções de classificação do fenômeno: se considerarmos que a modalidade já estava lá, escondida por detrás da vírgula, ela teria sido (I) eliminada - tendo-se eliminado a vírgula - do texto na primeira versão francesa e (IVb) reforçada, na segunda, pelos valores explicitados por "souvent" e "parfois" (frequentemente e por vezes); caso consideremos que essa vírgula não tenha nada o que esconder, nenhuma motivação semântica implícita ou explícita, nada se perde com a sua supressão em 1992, e (II) acresce-se a modalidade, de forma explícita, em 2005.

[k] [de konklusões] Após o exame minucioso de [a] a [j], comprova-se, em partes, a validade de nossa hipótese: com suas frequentes, e por vezes engenhosas modificações nas modalidades presentes no texto de Machado de Assis - cerca de (duas) eliminações, (seis) acréscimos, alterações de tipo (três), grau (sete) e incidência (uma), além de profundas reformulações sintagmáticas sem alteração da modalidade (uma) (até agora) -, constata-se que a versão de 2005 pende, de fato, e fortemente, para a tradução domesticadora, enquanto a de 1992 - com somente três eliminações e

9 Nossa tradução: “a hierarquia que o enunciador impõe aos diferentes componentes de seu discurso”. 
dois acréscimos de modalidade, mais uma alteração de grau (outrossim até agora) toma mais o partido dos estrangeirizadores, voluntária ou involuntariamente, levando-se ou não em conta o posicionamento da tradutora consoante a esses termos específicos; enquanto a versão mais antiga tenta seguir a ordem das palavras do original, a carga semântica das modalidades, a estrutura sintagmática etc., a mais recente se desprende com certa facilidade do original, permitindo-se liberdades dentre elas, uma patente inserção do eu, da subjetividade do próprio tradutor no texto - que demonstram seu caráter domesticador, sua preocupação em não deixar transparecer - demais - ao leitor que aquele texto é uma tradução do português, dando-lhe a impressão de que o que lê foi originalmente escrito em língua francesa, proporcionando-lhe uma leitura mais fluida, sem empecilhos, assim como se caracteriza a domesticação de que nos fala Venuti (1995, p. 2).

Tudo isso será reforçado daqui a pouco, através de um rápida investigação dos elementos paratextuais das duas edições; mas, visando a conclusão da análise acima, [k] é-nos também de grande valia, exatamente como apoio a nossas constatações: "A ferocidade [...] é o grotesco a sério", traduzido por "La férocité [...] est le grotesque doublé de sérieux" (1992), não sofre grandes mudanças, ou talvez torne-se uma modalidade complexa - em que (II) acrescenta-se uma modalidade nova em combinação com a pré-existente - e (IVb) ganhe em força na apreciação negativa (axiológica), implícita no original, porém explicitada por “doublé de sérieux” (envolta por seriedade); ao passo que, em "Sont féroces [...] les grotesques qui se prennent au sérieux", não somente ocorrem, como em 1992, o (II) aparecimento de uma modalidade complexa e o (IVb) reforço no grau de outra com a introdução de "se prennent au sérieux" (se levam a sério), mas também, tomando-se a frase por inteiro pois é toda ela um julgamento de valor do personagem -, temos um primeiro - e único - exemplo de (VIb) profunda reformulação sintagmática com alteração da modalidade.

Enfim, vimos pela análise do trecho selecionado que, de fato, em comparação com L'Aliéniste de 1992, a versão de 2005 apresenta um forte caráter domesticador, impregnada que está de um eu, de uma subjetividade que não é a do autor d'O Alienista, mas a da tradutora. É evidente que, passada mais de uma década entre uma edição e outra, a tradutora poderá ter adquirido mais prática, conhecimento e outras convicções, e tudo isso será refletido em sua nova tradução; mas o mercado editorial pode igualmente tê-la influenciado: a sua subjetividade pode também estar impregnada de outras subjetividades - e/ou objetividades - em que ela se insere. Nosso objetivo não é, porém, distinguir as escolhas da tradutora daquelas das editoras, tampouco identificar as razões que fundamentam tais escolhas, mas somente investigá-las no papel, no que está impresso. Passamos assim a uma breve análise dos elementos paratextuais que podemos observar nas duas edições de L'Aliéniste em questão, ainda no intuito de verificar o quão estrangeirizadoras ou domesticadoras são uma e outra.

Primeiramente, na edição de 1992, a contracapa informa que trata-se de uma tradução do "portugais", da língua portuguesa; já na de 2005, lê-se "traduit du brésilien" (traduzido do brasileiro). Ora, quem é esse "brasileiro": Machado de Assis, a língua brasileira?... Sendo mais provável que se refira à língua que se fala no Brasil, qual o termo que deveríamos encontrar ali? A opção de qualquer estudante de línguas seria ou o simples "portugais" de 1992, ou um “portugais brésilien”, e não o "brésilien” de 2005, o que nos leva a concluir que "brésilien” sugira uma postura domesticadora, uma preocupação em facilitar ao máximo a vida do leitor e logo lhe 
informar que o autor vem do Brasil, sem que ele tenha de se perguntar se, nesse país, fala-se português, ou se existem outros países em que essa língua é também falada... O mesmo poderá se depreender das notas de rodapé.

Quanto às notas, portanto, encontramos somente uma (explicando o que é uma "matraca", 2005, p. 41) na edição mais recente, unilíngue, uma que, aliás - sem sabermos por que - , não figurava na edição bilíngue (e que faz falta ali, em 1992, p. 59); já nesta edição (de 1992), temos uma dezena de notas explicativas para termos estrangeiros mantidos em português (em itálico) na tradução, termos referentes a animais, regiões, particularidades da cultura estrangeira da qual se traduz. $\mathrm{Na}$ tradução de 2005, no entanto, esses termos são, na sua grande maioria, domesticados, ou seja, empregados sem nenhuma explicação, como se fossem, de certa forma, desimportantes (por exemplo, "Botafogo" [2005, p. 36], que levava uma nota em 1992 [p. 45]), ou eliminados ("boiadeiro de Minas" [1992, p. 36] torna-se simplesmente "éleveur de bétail" [2005, p. 32], criador de gado, enquanto era “éleveur de bestiaux dans le Minas” em 1992 [p. 37], ainda com direito a uma nota explicativa para "le Minas"), ou substituídos por um hiperônimo, isto é, um termo mais genérico e em comum com a língua francesa (“caçador de pacas” [1992, p. 18] transforma-se em um simples "chasseur" [2005, p. 25], caçador, sem as "pacas" que eram mantidas e descritas em nota em 1992 [p. 19]).

Seguindo a mesma via da domesticação, não se acentuando as diferenças culturais entre a França e o Brasil, retornamos ao tema de "Itaguaí", nome próprio (topônimo) que é retomado tal e qual em 1992, porém afrancesado pelo trema em 2005 (“Itaguaï”): o mesmo ocorre, por exemplo, com o nome do protagonista, o doutor Bacamarte, que continua sendo Simão em 1992, mas se torna em 2005, a la francesa, "Simon". E esses exemplos ajudam-nos a comprovar a validade da hipótese de que essas edições se distinguem enormemente no que concerne à estrangeirização e à domesticação, sendo a última estratégia muito mais patente na versão unilíngue.

De forma semelhante, um outro componente importante do paratexto - e útil a nossa análise em geral - é o prefácio: enquanto ele é escrito pela própria tradutora em 1992 - e ainda acompanhado de uma dúzia de páginas com fotos e comentários sobre o autor e o contexto da época em que foi escrita a narrativa -, o prefácio de 2005 consiste em uma espécie de estudo histórico-filosófico-literário sobre a loucura, em que essas áreas do conhecimento convergem para comentar - en passant, somente - o texto de Machado, mas também divergem dele em grande parte do tempo. Portanto, ao contrário do primeiro, esse prefácio tem o claro objetivo de oferecer conhecimentos gerais da cultura ocidental, domésticos, muito mais do que trazer informações estranhas, estrangeiras ao leitor, conhecimentos e/ou questionamentos específicos no que diz respeito à língua do original e às suas relações com a cultura ligada a ela, à tradução e a tudo o que implica a atividade tradutória.

Por fim, acreditamos ter ficado suficientemente evidente que cada uma dessas edições, apesar de portarem a assinatura da mesma tradutora, apresenta tanto textos quanto paratextos distintos e reveladores de estratégias igualmente distintas. Quanto às traduções em si, graças à teoria da modalização de Pottier e aos estudos de Carreira relacionados, deixamos claros, de um lado, o caráter mais estrangeirizador da publicação bilíngue de 1992 - onde o esforço é o de se manterem as modalidades linguísticas, as marcas da subjetividade do autor do original - e, de outro, o cunho mais domesticador da unilíngue de 2005 - em que o eu, a subjetividade do tradutor, às vezes chega a obnubilar a do autor. Voltando a Schleiermacher, mencionado agora não por Britto, mas por Venuti (1995, p. 20), e aplicando suas concepções de tradução 
aos objetos deste nosso estudo, a tradutora Maryvonne Lapouge-Pettorelli, com a edição unilíngue de 2005, doma os alienígenas d'O Alienista antes de levá-los para visitar a casa do leitor francês, enquanto que, com o L'Aliéniste bilíngue de 1992, ela toma o leitor francês pela mão e o traz para conhecer a casa dos aliens.

José Roberto Andrade Féres

andradeferes@yahoo.com.br

Universidade Federal da Bahia

\section{Referências}

ASSIS, Machado de. L'Aliéniste. Tradução de Maryvonne Lapouge-Pettorelli. (Folio Bilingue, n. 25.) Paris: Gallimard, 1992.

L'Aliéniste. Tradução de Maryvonne Lapouge-Pettorelli. Paris: Éditions Métailié, 2005.

BRITTO, Paulo Henriques. Tradução e ilusão. Estudos Avançados. São Paulo, v. 26, n. 76, 2012, p. 21-27. Disponível em: <http://www.revistas.usp.br/ eav/article/view/47535> Acesso em: 31 ago. 2013.

CARREIRA, Maria Helena de Araújo. Modalisation linguistique en situation d'interlocution: Proxémique verbale et modalités en portugais. Louvain; Paris: Éditions Peeters, 1997.

- Semântica e discurso: estudos de linguística portuguesa e comparativa (português/francês). Porto: Porto Editora, 2001.

JAKOBSON, Roman. Linguística e comunicação. 22 ed. Tradução de Izidoro Blikstein e José Paulo Paes. São Paulo: Cultrix, 2010.

POTTIER, Bernard. Sémantique Générale. Paris: Presses Universitaires de France, 1992.

. Représentations mentales et catégorisations linguistiques. Louvain; Paris: Éditions Peeters, 2001.

VENUTI, Lawrence. The translator's invisibility: a history of translation. Londres; Nova York: Routledge, 1995. 